УДК 316

$10.17213 / 2075-2067-2020-3-109-117$

\title{
ЭКОЛОГИЧЕСКОЕ ПОВЕДЕНИЕ В КОНТЕКСТЕ СОЦИОЛОГИЧЕСКОЙ ТЕОРИИ
}

\author{
(C) 2020 г. B. A. Захарова \\ Крымский филиал Федерального научно-исследовательского \\ социологического центра РАН, г. Симферополь, Россия
}

Целью исследования является обоснование сущности и специфики экологического поведения как широкого комплекса сочииальных взаимодействий, обусловленных факторами среды и характеристиками самого глобального общества, представляющего собой разновидность социального поведения либо действия, которое подлежит классификации с учётом типологий, сложившихся в теоретической социологии.

Методологическую базу исследования представляют классические социологические теории (Э. Дюркгейм, М. Вебер и др.), потенциал которых не исчерпан в прочессе изучения и осмысления рассматриваемой проблематики. Исследование базируется также на идеях ряда современных западных исследователей (Дж. Робертс, П. Стерн и др.), подчеркивающцих роль социокультурных факторов в формировании мотивации экологического поведения. К методологии исследования примыкает культурсочиология Дю. Александера и рискологический подход (У. Бек).

Результаты исследования. Содержание экологического поведения в современной социиологии, как правило, раскрывается сквозь призму институциионализированной (экологической) культуры, формирующей иенностное измерение индивида на основе солидарности в отношении общего блага. Поскольку поведение людей в отличие от поведения животных носит в значительной степени осмысленный характер, то ключевая роль в его изучении отводится нами рассмотрению сочиального (экологического) действия, которое в ијелом является структурным элементом экологического поведения.

Перспективу исследования составляет дальнейший социологическкий анализ экологического поведения различных соииальных групп.

Ключевые слова: экологическое поведение; сочиальное поведение; сочиальное действие; общество; культура.

\section{ECOLOGICAL BEHAVIOR \\ IN THE CONTEXT OF SOCIOLOGICAL THEORY}

\author{
(C) 2020 V. A. Zakharova \\ Crimean Branch of the Federal Research Sociological Center, \\ Russian Academy of Sciences, Simferopol, Russia
}

The purpose of the study is to substantiate the essence and specificity of environmental behavior as a broad set of social interactions caused by environmental factors and characteristics of the global society itself, which is a type of social behavior or action that is subject to classification taking into account the typologies that have developed in theoretical sociology. 
The methodological base of the study is represented by classical sociological theories (E. Durkheim, M. Weber, etc.), the potential of which is not exhausted in the process of studying and understanding the issues under consideration. The research is also based on the ideas of a number of modern Western researchers (J. Roberts, P. Stern, etc.), who emphasize the role of socio-cultural factors in the formation of motivation for environmental behavior. The research methodology is joined by J. Alexander's cultural sociology and the risk approach (W. Beck).

The results of the study. The content of ecological behavior in modern sociology is usually revealed through the prism of an institutionalized (ecological) culture that forms the value dimension of an individual based on solidarity with the common good. Since human behavior, in contrast to animal behavior, is largely meaningful, the key role in its study is assigned to the consideration of social (ecological) action, which in General is a structural element of environmental behavior.

The prospect of the study. Further sociological analysis of the ecological behavior of various social groups provides a perspective for the research.

Key words: environmental behavior; social behavior; social action; society; culture.

Введение. Закономерность в поведении человека (как и его зависимость от биотических процессов окружающей среды), обусловленная его общественными связями и включенностью в социальные системы, выступает важным предметом социологических исследований, который нашёл своё отражение в таких ключевых концепциях современной теории, как «понимающая» социология М. Вебера $[1,2]$, структурно-функциональный анализ Т. Парсонса $[3,4]$, теория «общества риска» У. Бека [5], концепция «социального капитала» П. Бурдьё [6] и ряде других ведущих направлений социально-гуманитарного знания. В данной связи можно говорить о том, что рассматриваемое нами экологическое поведение - широкий комплекс социальных взаимодействий (обусловленных факторами среды и характеристиками самого глобального общества), представляющий собой разновидность социального поведения (либо действия), которое подлежит классификации с учётом типологий, сложившихся в теоретической социологии, поэтому методология изучения экологического поведения социологическими средствами в той или иной степени должна интегрировать в себя культуральные способы осмысления социальной действительности. В данной связи существенную значимость приобретает веберовский подход к осмыслению данного типа поведения. Таким образом, признанные в настоящее время подходы, направленные на изучение экологического поведения, представленного в рам- ках современной социологии, существенно выходят за рамки психологии классического бихевиоризма, в значительной степени полагаясь на специфику экологической культуры, способной оказывать перманентное влияние на действия и поведение различных социальных акторов [7, 8].

Ведущие методологические подходы изучения экологического поведения. Рискологический характер современного общества во многом обусловлен именно экологической проблематикой, которая способствует коррекции классических социологических теорий. Вместе с тем необходимо иметь в виду, что если классики социологии (Э. Дюркгейм [9] и М. Вебер $[1,2])$ не дали дескрипции экологического поведения, поскольку в период создания их теорий экологическая проблематика не была так широко распространена как в науке, так и в общественном сознании, то это не значит, что разработанный ими методологический аппарат не может быть использован в ряде современных исследований (посвященных изучению экологического поведения). Более того, потенциал классических социологических теорий ещё вовсе не исчерпан в процессе изучения и осмысления рассматриваемой нами проблематики.

Социальное поведение человека, особенно если речь идёт о сложном комплексном поведении, не существует вне зависимости от культурной интериоризации и постоянного воздействия на него значимых символов. 
Очевидно, что само отношение человека к природе зачастую носит ярко выраженный эмоциональный характер. Например, мы часто замечаем, как у человека резко поднимается настроение во время редких выездов на природу из душных городских агломераций. С другой стороны, и в современных городах создаются крупные «зелёные» зоны, являющиеся неотъемлемым компонентом создания экологического ландшафта. «Идеи, влияющие даже на самые современные общества, - как справедливо в данной связи подметил Дж. Александер, - не представляют собой когнитивные вместилища подтвержденных фактов; они суть символы, которые продолжают формироваться глубокими эмоциональными импульсами и определяться исполненными смысла ограничениями» [10]. Вышеприведенное суждение в полной мере может быть отнесено и к экологическому поведению, которое в значительной степени проникнуто символической реальностью.

Неудивительно и то, что представления о «чистой» (или «нетронутой» или даже о «матушке») природе представляют собой эмоционально-заряженные концепты, способные постоянно продуцировать суггестивные образы, которые порой очень сильно влияют на человеческое поведение и социальные установки акторов в целом. Принято различать внутренние (знания, ценности, мотивации) и внешние (экологическая политика, образование) факторы формирования экологического поведения. Ряд современных западных исследователей (Дж. Робертс [11], П. Стерн [12] и др.) также подчеркивали роль социокультурных факторов в формировании мотивации экологического поведения. Вместе с тем для трансформации экологического поведения необходимым является процесс экологической социализации, в результате которого внешние факторы его формирования приобретают свойства внутренних установок.

Область изучения экологического поведения сопрягается и находится в постоянном взаимодействии с медицинскими компонентами его социализации, здоровым образом жизни индивида и его биологической безопасности, поэтому в целом можно сказать, что реакция индивида на стимулы (со стороны внешнего окружения), включая и рассматриваемые нами экологические вызовы и риски, в большинстве случаев «опосредована» имеющимися в его распоряжении (интериоризированными) ценностями культуры (М. Вебер) и вполне сформированным социальным «габитусом» (П. Бурдьё). Сценарии экологического поведения, не удовлетворяющие требованиям социальной безопасности, могут быть довольно сильно укоренены в привычках и практиках субъектов социальной деятельности, что порой требует довольно серьёзной коррекции и даже прямого государственного вмешательства, более совершенного регулирования данной области социальных отношений.

Оказывается, что в той или иной степени основой экологического поведения выступает социальный обмен, совершаемый, как правило, между акторами в форме дарения либо на основе взаимовыгодного сотрудничества. Так само социальное поведение представляет собой взаимодействие двух или более акторов, которые обладают общими (пускай и опосредованными) интересами. Социальное поведение регулируется правовыми нормами и неофициальными (неписаными) традициями. В отличие от других животных человек способен планировать будущее своего вида на многие десятилетия вперёд, что в значительной степени усиливает его (видовую) способность к выживанию и развитию. Социальное поведение населения большинства стран направлено на поиск материальных благ, добываемых главным образом при помощи труда.

Таким образом, индивиды оказываются заинтересованы в адекватных действиях со стороны других членов общества, которые не в последнюю очередь направлены на поддержание стабильности и безопасности. Согласно определению, данному Э. Дюркгеймом, социальными «обозначают почти все происходящие в обществе явления, если последние представляют хоть какой-нибудь социальный интерес» [9]. Однако в последнее время мы наблюдаем противоречие между экономическими интересами людей, вернее сказать, между определенными интегрированными бизнес-группами с одной стороны и требованиями экологической безопасности с другой. В настоящее время на фоне развития техногенной цивилизации и роста угроз, связанных с негативными последс- 
твиями глобальной индустриализации, резко повысилась социальная значимость самого экологического поведения. На практике оказывается, что экологическая безопасность становится важным критерием социальной стратификации, поскольку, например, обеспеченным людям намного легче выбрать для проживания экологически более приемлемые территории для безопасной жизни.

Несмотря на проявление и всплески спонтанности в общественной жизни, сощиальное поведение во многих случаях носит вполне осмысленный характер, более того, оно в значительной степени детерминировано культурой. «Поведение, - замечает П. Штомпка, снабженное значением, смыслом, называется в социологии действием» [13]. Но вместе с тем в социологии принято различать такие понятия, как «социальное поведение», от «социального действия». Второе («социальное действие») является частным или более конкретным случаем первого («социального поведения»). Социальное поведение ответная реакция на воздействие со стороны (внешних раздражителей) среды, соответственно, оно может быть неосознанным или ненамеренным, а, следовательно, и далеко не всегда разумным (достаточно вспомнить случаи массового психоза и паники), тогда как социальное действие - преднамеренные поступки, обусловленные дискретными культурными паттернами и вполне различимыми ценностными установками.

На практике оказывается, что именно социиальное действие выступает структурообразующим элементом социального поведения человека, без наличия которого поведение людей мало бы чем отличалось от поведения других представителей животного царства, поэтому важной чертой социального поведения человека является разделение на субъективную и объективную сторону действия, сопровождающееся оценкой ситуации. Значит, именно социальное действие способно продемонстрировать нам субъектность актоpa, его способность принимать свободное решение в отношении необходимой ситуации, a, следовательно, и брать на себя ответственность за последствия неудачного выбора.

В процессе социального действия актор в большей степени стремится к осознанию собственной потребности, хотя и не во всех случаях может контролировать своё поведение. «Действие - это некоторый процесс в системе «субъект - объект - ситуация», имеющий мотивационное значение с точки зрения мотивации действующего индивида или, в случае коллектива, мотивации составляющих его индивидов» [4]. Ясно также, что мотивация действия, как правило, направлена на удовлетворение возникающих у индивида потребностях (материального, морального, эстетического свойства).

Вместе с тем главным образом из теории М. Вебера нам известно, что далеко не все типы социального действия соответствуют критериям научной рациональности, что в особенности необходимо учитывать применительно к широкому спектру проблем экологического характера.

Так, например, согласно веберовской концепции социальное действие может быть представлено четырьмя «идеальными» типами:

- целерациональным (инструментальнblм) — это действие, в основе которого лежит ожидание событий внешнего мира или действий других людей и использование данного ожидания в собственных интересах (для достижения поставленной и продуманной цели);

- иенностно-рациональныл - это действие, которое базируется на вере в безусловную самодовлеющую ценность (эстетическую, религиозную, этическую и др.) вне зависимости от того, к чему оно может привести (и какие выгоды сулит актору). Зачастую данное действие сопряжено с моральным долгом;

- аффективным - обусловленным эмоциональным состоянием индивида (действием аффекта). Зачастую является причиной потери индивида контроля над своими действиями;

- традиционнылм, которое сформировано под влиянием длительной привычки [1].

Последние два типа действия не являются рефлексивными, что уже предполагает их значительную зависимость от общественного мнения (по ряду данных вопросов) либо от прямого воздействия сил природы (например, инстинктов, эмоций и склонностей).

Очевидно, что и экологическое поведение может включать в себя различные типы социального действия, то есть быть как ценностно-рациональным или цуелерациональным, 
а в результате длительной привычки становиться традициионнылм и, пожалуй, в некоторых аспектах даже может принимать ярко выраженный аффективнылй характер.

Беречь природу можно не только из утилитарных установок рационального свойства, но также из «мистического» переживания своего единства с ней или даже из страха наказания со стороны потусторонних сил. Не секрет поэтому, что экологическое поведение может быть обусловлено религиозным мировоззрением и соответственно носить вполне откровенно религиозный характер [14]. Но вместе с тем в результате социализации и воспитания подрастающего поколения необходимо акцентировать внимание в первую очередь на его научно-верифицируемых аспектах.

Приемлемое отношение к природе (включая экологию человека) должно быть институциализировано и в определенном смысле превратиться в элемент будущей традиции. В сложившейся ситуации прерогатива принятия наиболее значимых экологических решений всё больше сдвигается в сторону формирования и внедрения «природоохранного» типа культуры, но пока в обществе продолжает доминировать тип потребительского поведения [15], который оказывается не так просто согласовать с социальным поведением, ориентированным на экологические ценности. При этом сами экологические ценности не являют собой универсального единства, а могут быть представлены в общественном сознании набором довольно разнообразных вариаций. В целом, однако, их может объединять стремление к здоровью и потреблению экологически чистых продуктов, а также практики экологического туризма. По-прежнему проблемным аспектом экологического поведения будет оставаться «зелёный» активизм, который может вступать в противоречие с властными решениями в отношении тех или иных хозяйственных проектов.

Влияние науки и техники на паттерны экологического поведения современного человека. В настоящее время человечество испытывает дефицит бережно-консервативного поведения по отношению к окружающей природе. Тем более, что во многих странах риски, связанные с загрязнением окружаю- щей среды, ещё полностью не осознаны. Конечно, можно говорить о том, что мы стоим перед радикальным выбором или «на перепутье: один путь — самоуничтожение, другой счастливая жизнь при разумном ограничении потребностей. Надеемся, разум возьмет верх и биосфера планеты перейдет в ноосферу сферу разума, а не в некросферу - сферу деградации и смертности» [16]. Очевидно также, что экологическое планирование и реализация соответствующих проектов (обеспечение экологической безопасности) может быть осуществлено только лишь при поддержке государственных и международных институтов, способных учитывать факторы глобальной экономической целесообразности.

Примерно начиная с середины XX века, в особенности после пика индустриализации и череды ядерных (военных) испытаний, в ведущих мировых державах были сформированы принципы радикального отказа от «эксплуатации природы», которые в свою очередь породили неформальную субкультуру «экологистов», изначально распространявшуюся в молодёжной среде (преимущественно развитых западных стран). Вместе с тем популяризируемый представителями данной субкультуры тип экологического поведения не получил достаточно широкого (массового) распространения в мире по причине содержащихся в нём явно утопических и радикальных аспектов [17]. Но с другой стороны многие представители глобального креативного класса (занятые в сфере высоких технологий) в определенной степени усвоили ценности данной субкультуры. Можно даже отметить, что идеологическое влияние «экологистов» вполне ощутимо в современной политике, особенно применительно к проблеме глобального потепления. «Вместо того, чтобы рассматривать природу как объект возможного технического распоряжения, мы могли бы относится к ней как партнеру возможной интеракции. Вместо природы эксплуатируемой мы могли бы стремиться к природе братской» [18]. Но также очевидно, что вышеописанный тип поведения в отношении окружающей среды крайне тяжело сделать преобладающим, особенно учитывая, что во многих развивающихся странах ещё только происходит интенсификация промышленного производства. 
Можно констатировать, что экологическое поведение интегрировано в систему общественных отношений таким образом, что оказывается наиболее тесно связанным как c проблемами социальной стратификации и разделения труда, так и с вопросами взаимодействия науки и техники с окружающей природной действительностью. Пожалуй, экологический образ жизни и стиль поведения может стать привилегией для наиболее обеспеченных социальных классов общества. Например, уже сейчас потребление экологически чистых продуктов и доступ к наиболее значимым рекреационным ресурсам земли имеют далеко не все слои и страты населения.

Кроме этого, рассматриваемое нами здесь экологическое поведение крайне тяжело отделить не только от культуры, но и от науки и техники, понимаемых в качестве институциализированных сфер общественной жизни. Можно вполне говорить о том, что появление основных экологических проблем совпадает с беспрецедентным прогрессом производительных сил человечества. Более того, рациональные стандарты человеческого поведения на протяжении целых веков конструировались, исходя из требований техники и ориентации на прогресс экспериментальных наук. В данной связи Ю. Хабермас справедливо отмечал, что «как бы то ни было, достижения техники, сами по себе непреложные, разумеется, невозможно заменить природой, хотя и смотрящей на нас открытыми глазами. Альтернатива существующей технике - проект природы как партнера, а не предмета, связана с альтернативной структурой деятельности: символически опосредованной интеракцией, отличной от целерационального действия» [18]. К тому же это потребует радикальной перестройки человеческого языка и всей культуры (включая политические системы большинства стран современного мира), что вряд ли приемлемо для современного человеческого общества. Попытки введения экологического авторитаризма также не стоит исключать из рассмотрения данной проблемы, поскольку радикальные экологисты зачастую оценивают жизнь других живых существ (зверей, птиц, растений) выше, чем жизнь самого человека.

На протяжении многих веков формировался порядок господства человека над природой, который в свою очередь привёл к снижению естественного отбора. «В развитии цивилизации обнаруживается фактор, который может быть описан как постепенное вытеснение естественного отбора рациональным действием. Выживание - или, скажем иначе, успех - зависит от адаптируемости индивида к тому давлению, которое общество налагает на него» [19]. Приспособление к требованиям науки, техники и системы социальной рационализации приобрело всеобщий характер, в ещё большей степени разрушив прежнюю (характерную для крестьянских сообществ) интимность отношений между человеком и природными объектами.

Таким образом, необходимо признать техникоцентричный и деятельностный характер современной науки, которая вряд ли способна отказаться от прежних завоеваний в деле покорения природы. Более того, экологическое поведение последних лет будет неминуемого тяготеть к цифровизации основ «безопасности жизнедеятельности» и решения природных вызовов. «Но коль малосодержательной является идея Новой Техники, столь же невозможно помыслить и идею некой Новой Науки, ибо наука в нашем контексте должна означать не что иное, как современную науку, обязанную ориентироваться на возможное техническое использование своих результатов. Таким образом, и для функций этой науки, ровно как и для научно-технического прогресса в целом, не существует никакой замены, которая была бы «гуманнее» того, что существует» [18]. Следовательно, и гуманизация экологического поведения будет осуществляться (хотим мы этого или нет) с опорой на последние научные разработки и высокие информационные технологии.

Вместе с тем нельзя полностью исключать, что экологическое поведение при высоком уровне культурного развития может стать в определенной степени традиционHblм, но при этом необходимо уметь осуществлять постоянный (рациональный) мониторинг новых экологических вызовов и угроз, а главное - не впадать в панику, вызванную климатическими изменениями или разрушением озонового слоя. При этом в настоящее время многие реально существующие экологические вызовы, с которыми столкнулась глобальная цивилизация, тем не менее, 
были превращены в «страшилки», используемые в конкурентной борьбе между группами, представляющими различные интересы в сфере энергетики.

Таким образом, само экологическое поведение, в отличие от многих других типов социального поведения, в большей степени должно быть ориентировано на осмысленность действий, достигаемых вследствие усвоения научных знаний. Вместе с тем, следуя установкам веберовской теории действия, необходимо вести речь о ценностном измерении экологического поведения, которое всё в большей степени должно принимать этический характер. Этизация экологического поведения должна компенсировать однобокость инструменталистского способа понимания и использования природной действительности, а также оказать влияние на формирование идентичности современного человека в сторону большего осознания себя гармоничной частью природы.

На практике оказывается, что экономический интерес может негативно сказываться на собственно экологическом поведении. Отдельного внимания в данной связи заслуживают процессы экономической коррупции, которые ещё в большей степени тормозят экологические практики и внедрение «зеленой» экономики, в результате чего перед акторами возникает серьёзная проблема правильной оченки сложившейся экологической ситуации. «В качестве внутренних барьеров на пути к экологическому поведению выступают неэкологические мотивы, которые являются более интенсивными и определяющими для человека по отношению к мотивам экологическим» [20]. Таким образом, акторы склонны в большей степени руководствоваться скорее тактическими, чем стратегическими установками в отношении преодоления экологических проблем.

Заключение. Проведенный нами анализ понимания экологического поведения в современных научно-исследовательских практиках позволил выявить эвристический потенциал ряда социологических теорий, способных стать методологической базой дальнейшего исследования. В целом было выяснено, что содержание экологического поведения в современной социологии, как правило, рас- крывается сквозь призму институционализированной (экологической) культуры, формирующей ценностное измерение индивида на основе солидарности в отношении общего блага. Поскольку поведение людей в отличие от поведения животных носит в значительной степени осмысленный характер, то ключевая роль в его изучении отводится нами рассмотрению сочиального (экологического) действия, которое в целом является структурным элементом экологического поведения.

В изучении экологического поведения наибольшей эвристической ценностью обладает, на наш взгляд, «понимающзая» соииология М. Вебера, методология которой позволяет описать действия акторов сквозь призму культурных ценностей. Вместе с тем веберовская теория открывает возможность классифицировать типы экологического поведения в зависимости от превалирующих в нём (четырёх) видов социального действия. К данной методологии в целом также примыкает культурсоциология Дж. Александера, в рамках которой акцентируется внимание на символических и аффективных аспектах социального поведения. Рискологический подход (У. Бек) позволяет рассматривать экологическое поведение в контексте угроз, появление которых во многом обусловлено развитием глобального общества «позднего модерна», а его трансформацию (и экологизацию) как реакцию на новые вызовы. При этом, однако, акторам (действующим в обществе риска) необходимо становиться на рефлексивную и одновременно оценочную позицию в экспликации рисков, на которую в свою очередь могут активно влиять медиа и другие институты социализации.

\section{Литература}

1. Вебер М. Избранное: Протестантская этика и дух капитализма. - М.; СПб: Центр гуманитарных инициатив; Университетская книга, 2014. - 656 с.

2. Вебер М. Образ общества. - СПб.: Центр гуманитарных инициатив, 2012. $767 \mathrm{c}$.

3. Парсонс T. О структуре социального действия. - М.: Академический проект, 2002. $-880 \mathrm{c}$.

4. Парсонс T. Социальная система. - М.: Академический проект, 2018. - 530 с. 
5. Бек У. Общество риска. На пути к другому модерну. - М.: Прогресс-Традиция, 2000. - $384 \mathrm{c}$.

6. Бурдье П. Социология социального пространства. - СПб: Алетейя, 2014. - 288 с.

7. Марар О.И. Экологическая культура в современном российском обществе: автореф. дис. ... доктора социолог. наук. - Москва, 2012. - 41 с.

8. Маршак А.Л. Глобальная экологическая культура общества как фактор формирования социальной толерантности // Общество и право, 2003. - №1. - С. 38-51.

9. Дюркгейм Э. Социология. Ее предмет, метод, предназначение. - М.: Канон, 1995. - $400 \mathrm{c}$.

10. Александер Дж. Смыслы социальной жизни: Культурсоциология. - М.: Праксис, 2013. - 344 c.

11. Roberts J.A. Green consumers in the 1990s: profile and implications for advertising// Journal of Business Research. — 1996. Vol.36. - №3. - Pp. 217-231.

12. Stern P. C. Toward a Coherent Theory of Environmentally Significant Behavior // Journal of Social Issues. - 2000. — Vol. 56. — №3. Pp. 407-424.

13. Штомпка П. Социология. Анализ современного общества. - М.: Логос, 2010. $244 \mathrm{c}$.

14. Евдокимов А.Ю. Проблемы религии и экологии // Вестник Московского государственного лингвистического университета. Гуманитарные науки. — 2016. - №23 (762). C. 176-194.

15. Ильин А. Н. Культура общества массового потребления: критическое осмысление. - Омск, 2014. - 208 с.

16. Агаджанян Н. А. Глобализация и экология человека // Журнал прикладной психологии. - 2002. - №3. - С. 56-59.

17. Макаренко В.П. Главные идеологии современности. - Ростов-на-Дону: Изд-во «Феникс», 2000. - 480 с.

18. Хабермас Ю. Техника и наука как «идеология». - М.: Праксис, 2007. - 208 с.

19. Хоркхаймер $M$. Затмение разума. К критике инструментального разума. - М.: «Канон+» РООИ «Реабилитация», 2011. $224 \mathrm{c}$.

20. Лазаревич Н. А. Факторы формирования экологического поведения // Труды БГТУ.
Серия 6: История, философия. - 2018. №1 (209). - C. 121-124.

\section{Referense}

1. Veber M. Izbrannoe: Protestantskaja jeti-ka i duh kapitalizma [Favorites: Protestant ethics and the spirit of capitalism]. - Moscow; SaintPetersburg: Centr gumanitarnyh iniciativ; Universitetskaja kniga, 2014. - 656 p.

2. Veber M. Obraz obshhestva [Image of society]. - Saint-Petersburg: Centr gumanitarnyh iniciativ, 2012. - $767 \mathrm{p}$.

3. Parsons T. O strukture social'nogo dejstvija [About the structure of social action]. Moscow: Akademicheskij proekt, 2002. - 880 p.

4. Parsons T. Social'naja Sistema [Social system]. - Moscow: Akademicheskij proekt, 2018. - $530 \mathrm{p}$.

5. Bek $U$. Obshhestvo riska. Na puti $\mathrm{k}$ drugomu modern [Risk society. On the way to another modern]. - Moscow: Progress-Tradicija, 2000. - $384 \mathrm{p}$.

6. Burd'e P. Sociologija social'nogo prostranstva [Sociology of social space]. - SaintPetersburg: Aletejja, 2014. — 288 p.

7. Marar O.I. Jekologicheskaja kul'tura $\mathrm{v}$ sovremennom rossijskom obshhestve: avtoref. dis. ... doktora sociolog. Nauk [Ecological culture in modern Russian society: Ph. D. (Social) Thesis]. - Moscow, 2012. - $41 \mathrm{p}$.

8. Marshak A.L. Global'naja jekologicheskaja kul'tura obshhestva kak faktor formirovanija social'noj tolerantnosti [Global environmental culture of society as a factor in the formation of social tolerance] // Obshhestvo i pravo [Society and law], 2003. - №1. - Pp. 38-51.

9. Djurkgejm Je. Sociologija. Ee predmet, metod, prednaznachenie [Sociology. Its object, method, purpose]. - Moscow: Kanon, 1995. - 400 p.

10. Aleksander Dzh. Smysly social'noj zhizni: Kul'tursociologija [Meaning of social life: Cultural sociology]. - Moscow: Praksis, 2013. - 344 p.

11. Roberts J.A. Green consumers in the 1990s: profile and implications for advertising // Journal of Business Research. - 1996. Vol.36. - №3. - Pp. 217-231.

12. Stern P.C. Toward a Coherent Theory of Environmentally Significant Behavior // Journal of Social Issues. - 2000. - Vol. 56. - №3. Pp. 407-424. 
13. Shtompka P. Sociologija. Analiz sovremennogo obshhestva [Sociology. Analysis of modern society]. - Moscow: Logos, 2010. — 244 p.

14. Evdokimov A. Ju. Problemy religii i jekologii [Problems of religion and ecology]// Vestnik Moskovskogo gosudarstvennogo lingvisticheskogo universiteta. Gumanitarnye nauki [Bulletin of the Moscow state linguistic University. Humanities]. — 2016. — №23(762). — Pp. 176-194.

15. Il'in A.N. Kul'tura obshhestva massovogo potreblenija: kriticheskoe osmyslenie [Culture of mass consumption society: critical thinking]. - Omsk, 2014. - $208 \mathrm{p}$.

16. Agadzhanjan N.A. Globalizacija i jekologija cheloveka [Globalization and human ecology] // Zhurnal prikladnoj psihologii [Journal of applied psychology]. - 2002. - №3. Pp. 56-59.
17. Makarenko V.P. Glavnye ideologii sovremennosti [The main ideologies of our time]. Rostov-on-Don: Izd-vo «Feniks», 2000. - 480 p.

18. Habermas Ju. Tehnika i nauka kak «ideologija» [Technology and science as «ideology»]. - Moscow: Praksis, 2007. — 208 p.

19. Horkhajmer M. Zatmenie razuma. K kritike instrumental'nogo razuma [An Eclipse of the mind. To the critique of instrumental reason]. - Moscow: «Kanon+» ROOI «Reabilitacija», 2011. - $224 \mathrm{p}$.

20. Lazarevich N.A. Faktory formirovanija jekologicheskogo povedenija [Factors of environmental behavior formation] // Trudy BGTU. Serija 6: Istorija, filosofija [The works of BGTU. Series 6: History, philosophy]. — 2018. №1 (209). — Pp. 121-124.

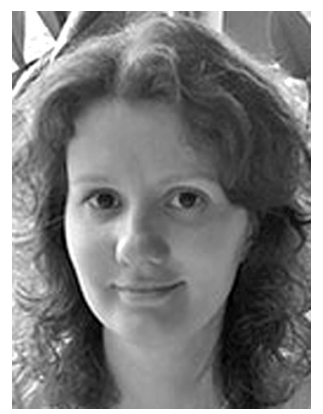

Захарова Вера Александровна - кандидат философских наук, старший научный сотрудник Крымского филиала Федерального научно-исследовательского социологического центра Российской академии наук. Специалист в области исследования экоправового воспитания, экологических практик и экологического поведения. Соисполнитель ряда региональных социологических исследований.

Zakharova Vera Alexandrovna - Candidate of Philosophical Sciences, Senior Researcher, Crimean Branch of the Federal Research Sociological Center, Russian Academy of Sciences. Specialist in the field of environmental education research, environmental practices and environmental behavior. Co-executor of a number of regional sociological studies.

295021 , г. Симферополь, ул. им. газеты «Крымская правда», 4 4 st. Name of the newspaper «Crimean truth», 295021, Simferopol, Russia

E-mail: zakharova7vera@mail.ru 